\title{
The usage of over the counter (OTC) medicines and traditional medicines (TMs) for common ailments in selected urban and rural areas in Sri Lanka
}

Risfa M.S ${ }^{1}$, Perera J.A.C ${ }^{1}$, Perera P.P.R ${ }^{2^{*}}$.

${ }^{1}$ B. Pharmacy Unit, Faculty of Medical Sciences, University of Sri Jayewardenepura, Gangodawila, Nugegoda, Sri Lanka. ${ }^{2}$ Department of Biochemistry, Faculty of Medical Sciences, University of Sri Jayewardenepura, Gangodawila, Nugegoda, Sri Lanka.

*Corresponding author e-mail: rasika@sjp.ac.lk

\section{Abstract}

Population-based studies regarding attitudes, knowledge, beliefs and practices of the use of non-prescription medicines and traditional medicines among the general public are rare in Sri Lanka. Public knowledge and understanding influence the pattern of self-medication. It will also provide further insight for the development and evaluation of health education and disease prevention strategies. Thus this study was conducted to investigate the usage of over the counter (OTC) medicines and traditional medicines (TM) for common ailments in a selected urban and rural area in Sri Lanka.

This descriptive cross-sectional study was conducted during June and July 2013 at Geli-Oya Muruthagahamula division (rural) and Bahirawakanda (urban) Gramaniladhari areas in Kandy District, Central Province, Sri Lanka. Volunteers $(n=400)$ between 18 65 years of age were selected by a random sampling method. An interviewer administered questionnaire was used to collect data from voluntary participants via a face to face interview. Written consent was obtained from participants before interviewing. Healthcare providers were excluded to avoid biased information.

Among the 400 participants (200 from each division) $82 \%$ had the opinion that selfmedication is enough to cure common ailments. Almost half of our respondents $(58 \%)$ were likely to practice both OTC drugs and TMs but TMs were preferred by many of the people in both areas $(61.25 \%)$. Younger adults (72\%) were using selfmedication more than the elderly people $(27.25 \%)$. Out of the respondents OTC drugs were preferred more by women and TMs were preferred by men. Accessibility of health care didn't have an impact on the choice of self-medication. Paracetamol $(97.50 \%)$ and the herbal preparation Samahan ${ }^{\circledR} \quad(56.75 \%)$ were the most frequently used OTC drugs and TMs respectively. There was a significant association ( $p<0.001$ ) between the use of self-medication and the area of study. The gender, age and family incomes showed significant associations with self-medication pattern (OTC drugs and TMs). The ease of handling and administration of OTC drugs is the more frequent reason to choose OTC drugs and main factor influencing the public's preference of TMs over the OTC 
drugs is the absence of serious side effects in TMs.

The usage of self-medication is widespread among people in both urban and rural areas and self-medication has significant association with the two selected areas. The major factor leading to the use of self-care behavior is patient satisfaction with the selfmedication system. The accessibility of health care services is not a factor that influences the choice of self-medication.

Keywords: Over the counter medicines, self medication, traditional medicines

\section{Introduction}

People all over the world suffer from common health problems. They legally have access to drugs by two mechanisms: access with a prescription provided by a licensed medical practitioner or access without a prescription, by self-medication ${ }^{1}$. For number of years there has been an increasing interest in a positive reassessment of the role of self-medication in health care $^{2}$. Self-care researchers demonstrate that the majority of care in illness involves self-treatment, not professional care; a self-medication has been shown to be a common first sort in illness ${ }^{3}$.

Self-care is defined as "what people do by themselves to keep their health, prevent and treat illness" by World Health Organization $(\mathrm{WHO})^{4}$. In other words self-medication refers to use of non-prescription medicines, usually over-the-counter (OTC) drugs, to treat certain 'minor' ailments themselves without consulting a medical practitioner and without any medical supervision ${ }^{5}$.

The time or cost required visiting a doctor to receive a prescription or refill often encourages patients to go for selfmedication ${ }^{6}$. It is also influenced by patient satisfaction with the healthcare provider, cost of the drugs, educational level, socioeconomic factors, age and gender. The increase in self-care is due to a number of factors such as socioeconomic factors, life style, ready access to drugs, the increased potential to manage certain illness through self-care, public health and environmental factors, greater availability of medicinal products and demographic and epidemiological factors ${ }^{7}$.

Self-medication also has advantages for healthcare systems as it facilitates better use of clinical skills of pharmacists, increases access to medication and may contribute to reducing prescribed drug costs associated with publicly funded health programs ${ }^{8}$. However, increasing availability of nonprescription medicines may encourage patients to believe that there is a drug treatment for every ailment. This may end up in serious adverse reactions.

Self-medication can be obtained either by using non-prescription (Over The Counter) medications in western or traditional medication or using home remedies.

The World Health Organization (WHO 2002) defines traditional medicine (TM), in part, as a medicine system that includes medication therapies like herbal medicines as well as non-medication therapies like acupuncture? 
In developing countries and in ethnic enclaves in industrialized countries, the affordability, availability, and cultural familiarity of traditional medicine, as well as family influence, contribute to the continued use of traditional medicines ${ }^{10}$.

On the other hand an increasing number of non-prescriptions, OTC medicines are available to treat an expanding range of ailments. OTC drugs are "drugs that can be purchased without the doctor's prescription" (Such as some analgesics, dermatologic products, anti-diarrheals, laxatives, antiemetics, antacids, anti-allergics etc.). Selfmedication products account for approximately $20 \%$ of the total international pharmaceutical market ${ }^{11}$.

\section{Methodology}

This descriptive cross sectional study was conducted in Geli-Oya, Muruthagahamula division (rural) and Bahirawakanda (urban) gramaniladhari areas in Kandy District of Central province, Sri Lanka.

The study sample consisted of volunteers between the ages of 18 years - 65 years. Samples of 200 volunteers each from the urban and rural area (total of 400) were recruited to the study by systematic random sampling. Healthcare providers were excluded to avoid biased information. Informed written consent was obtained from participants before interviewing. The study protocol was approved by the Ethics Review Committee of the Faculty of Medical Sciences, University of Sri Jayewardenepura.

\section{Results and discussion}

The age of the study population $(n=400)$ ranged from 21-65 years. The mean age of the study population was 42 years. Of the respondents, $82 \%$ had the opinion that selfmedication is enough to cure common ailments. But some of them used to consult a doctor if they found no improvement with self-medication. This finding confirmed that the use of self-medication was widespread among the people both in urban and rural area and is consistent with results of previous studies in Thailand ${ }^{11}$ and Kuwait ${ }^{4}$.

Factors influencing self-medication seemed to be patient satisfaction with the selfmedication, cost of drugs, educational level, socioeconomic factors, age and gender. A regional study conducted in Nepal concluded self-medication (59\%) was often the simplest option for the patients as the health care services in Nepal were difficult to be accessed $^{12}$. However accessibility of health care services doesn't seem a factor to influence the choice of self-medication in our research, as all participants had a private or government health care institution within three kilometres. On the other hand in Western countries cost and convenience had been the main factors influencing the choice $^{13}$.

Findings of this study show that women have chosen significantly more selfmedication than men. Out of them, OTC drugs were preferred more by women and TMs were preferred by men (Table 1). A possible reason for this may be that the majority of the responded males were from the rural area. 
Self-medication by elderly people who were over 50 years of age accounted for $27.25 \%$ of total respondents, which was pretty much lower when compared to the respondents who were aged below 50 years (72\%) (Table 1). A survey of self-reported medicine use in Japan $^{14}$ says that young adults were less likely to consult a doctor due to medical cost as $50 \%$ of them were anxious about their future medical expenses, whereas the elderly adults were less likely to see a doctor because of lack of transportation facilities. It may be one of the reasons in the case of young adult in our research study too.

Almost half of our respondents (58\%) were more likely to use both OTC drugs and TMs and TMs were preferred by many of the people $(61.25 \%)$ in both areas (Table 1). There were people who only stick to OTC drugs without trying any TMs. However the usage of TMs is comparatively high in rural area than the urban. This may be because of the herbs which were used for TMs are found easily in the nearby forest around the rural area and readily available in the courtyard of houses. This enables easy access of TMs.

Furthermore, use of TMs was positively associated with socioeconomic status and the educational level of respondents (Table 1). Most of the rural respondents were educated below Ordinary Level (O/L) and their income level is also low. There were also cultural factors in play, since the respondents had been born into a culture where herbal medicines would have been experienced from an early age.

Table 1: Selected demographic characteristics and usage of OTC medicines and traditional medicines $(n=400)$

\begin{tabular}{lcccc}
\hline \multicolumn{1}{c}{ Characteristic } & $\begin{array}{c}\text { OTC medicine } \\
\text { only }\end{array}$ & TM only & Both & P- value \\
\hline Sex Male & $26(40.00 \%)$ & $60(60.60 \%)$ & $112(47.86 \%)$ & 0.023 \\
\multicolumn{1}{c}{ Female } & $39(60.00 \%)$ & $39(39.40 \%)$ & $122(52.14 \%)$ & \\
\hline Age $<50$ years & $54(83.07 \%)$ & $57(57.57 \%)$ & $178(76.07 \%)$ & $<0.001$ \\
$\geq$ 50 years & $11(16.92 \%)$ & $42(42.42 \%)$ & $56(23.93 \%)$ & \\
\hline Area Rural & $18(27.69 \%)$ & $54(54.54 \%)$ & $128(54.70 \%)$ & $<0.001$ \\
$\quad$ Urban & $47(72.31 \%)$ & $45(45.45 \%)$ & $106(45.30 \%)$ & \\
\hline Educational level & & & \\
$\leq$ G.C.E. (O/L) & $17(26.15 \%)$ & $40(40.40 \%)$ & $85(36.32 \%)$ & 0.167 \\
$>$ G.C.E. (O/L) & $48(73.85 \%)$ & $59(59.60 \%)$ & $149(63.68 \%)$ & \\
\hline Monthly income & & & & \\
(SL Rupees) & & & $114(48.72 \%)$ & 0.007 \\
$<$ 30,000 & $19(29.23 \%)$ & $52(52.52 \%)$ & $120(51.28 \%)$ & \\
$\geq 30,000$ & $46(70.77 \%)$ & $47(47.48 \%)$ & \\
\hline
\end{tabular}


The participants who reported that they prefer OTC drugs emphasized the ease of handling and administration of OTC drugs, fast relief and ease of access had made them to choose OTC drugs over TMs (Table2). This was similar to the studies conducted in some of the other South Asian countries ${ }^{7,12}$.

Table 2; Reasons for preferring OTC medicines over traditional medicines.

\begin{tabular}{ccccccc}
\hline \multirow{2}{*}{ Reason } & \multicolumn{2}{c}{ Rural } & \multicolumn{2}{c}{ Urban } & \multicolumn{2}{c}{ Total } \\
\cline { 2 - 7 } & Frequency & $\%$ & Frequency & $\%$ & Frequency & $\%$ \\
\hline Due to fast relief & 67 & 63.80 & 70 & 36.08 & 137 & 67.82 \\
\hline $\begin{array}{c}\text { Easy to handle \& } \\
\text { administer }\end{array}$ & 61 & 58.09 & 46 & 47.42 & 107 & 52.97 \\
\hline Ease to access & 21 & 20.00 & 20 & 20.61 & 41 & 20.29 \\
\hline Other & 6 & 5.71 & 8 & 8.24 & 14 & 6.93 \\
\hline
\end{tabular}

But the main factor found to influence the public's preference of TMs over the OTC drugs were the absence of serious side effects in TMs (Table 3). This result resembles many other previous studies ${ }^{10,11,}$ 15

Table 3. Reasons to prefer traditional medicines over OTC medicines.

\begin{tabular}{ccccccc}
\hline \multirow{2}{*}{ Reason } & \multicolumn{2}{c}{ Rural } & \multicolumn{2}{c}{ Urban } & \multicolumn{2}{c}{ Total } \\
\cline { 2 - 7 } & Frequency & $\%$ & Frequency & $\%$ & Frequency & $\%$ \\
\hline Get cured & 66 & 51.56 & 49 & 41.88 & 115 & 46.93 \\
\hline $\begin{array}{c}\text { Safe to use/No } \\
\text { serious Side effects }\end{array}$ & 96 & 75.00 & 102 & 87.18 & 198 & 80.82 \\
\hline Economical & 46 & 35.93 & 18 & 15.38 & 64 & 26.12 \\
\hline Ease to access & 40 & 31.25 & 8 & 6.83 & 48 & 19.59 \\
\hline Other & 15 & 11.72 & 10 & 8.54 & 25 & 10.20 \\
\hline
\end{tabular}


Self-medication varied significantly with income. Like previous study in Nepal ${ }^{12}$ we found that choice of self-medication system was associated with family income (Table 1). Compared to people with a high income, people with lower income managed with TMs rather than buying OTC drugs.

The areas were ethnically diverse. The respondents were Sinhalese (52.2\%), Muslims (28.25\%), Tamils (18.25\%) and Burgers $(1.25 \%)$ and their percentages decreased respectively. The race of the respondents had a significant variation with the usage of self- medication. Only the burgers use more OTC drugs compared to TMs. The rest of the races in the population used more TMs for their self-medication.

The most frequently mentioned common ailment for self-medication were common cold $(73.0 \%)$ and cough $(57.0 \%)$ followed by fever $(56.25 \%)$, and other common symptoms such as body pain (51\%), and Headache (40.75\%).

Analgesics (mostly paracetamol), antacids and anti-histamines were the most commonly used classes of drugs in OTC medicines. When the TMs were concerned, Samahan (a brand name) has been used predominantly by both rural and urban people. The usage of herbs which are readily available such as ginger, coriander, nutmeg, was high among the rural people. On the other hand readymade products such as "paspanguwa" and analgesic balms were used more by urban respondents. This may be due to the lesser time taken for their preparation and administration.
Pharmacies and groceries had been the places where the respondents purchased the OTC drugs for their self-medication. The important information sources of OTC drugs seemed to be previous experience or prescription of the same medicine. However nearly $50 \%$ of the information was given by the pharmacists. A study in Ireland too found that a recommendation by a pharmacist most frequently influenced consumer/patients' choice of OTC medicines ${ }^{8}$ which was similar to that of $\operatorname{Jordan}^{16}$.

This study showed that the practice of treating ailments using TMs has been acquired from parents and grandparents $(82.8 \%)$ and previous experience of treating similar ailments had also had a significant influence.

It is generally assumed that usage of selfmedications differs between rural and urban areas. Our study too shows that more frequent users of self-medication were rural respondents. There was a rise in the number of people who use self-medication from that previously reported elsewhere ${ }^{8,17-19}$ which may reflect the public's growing confidence in self-medication.

\section{Conclusion}

The public opinion is that self-medication is enough to cure common ailments. The usage of self-medication is widespread among people both in urban and rural areas. The major factor leading to the use of self-care behavior is patient satisfaction with the selfmedication. The gender, age and family 
incomes have significant associations with self-medication pattern of OTC drugs and TMs.

Ease of handling and administration of OTC drugs is the main reason to choose OTC drugs and the main factor that influences the public's preference of TMs over the OTC drugs is the perceived absence of serious side effects in TMs.

Analgesics (mostly Paracetamol), antacids and anti-histamines were the most commonly used classes of drugs in OTC medicines and Samahan (a brand) is widely used as TM.

\section{Acknowledgement}

The authors acknowledge the Grama Niladhari's (Local government agents) of the Bahirawakanda and Gelioya areas for their assistance and the participants of this study.

\section{Conflicts of interest}

The authors declare no conflicts of interest.

\section{References}

1. Wood AJ, Brass EP. Changing the status of drugs from prescription to over-thecounter availability. New England Journal of Medicine. 2001;345(11):810-6.

2. Cranz H. Over-the-Counter drugs. Drug Safety. 1990;5(1):120-5.

3. Pylypa J. Latino immigrants: Selfmedication practices in two California Mexican communities. Journal of Immigrant Health. 2001;3(2):59-75.
4. Abahussain E, Matowe LK, Nicholls P. Self-reported medication use among adolescents in Kuwait. Medical principles and practice. $2005 ; 14(3): 161-4$.

5. Du Y, Knopf H. Self-medication among children and adolescents in Germany: results of the National Health Survey for Children and Adolescents (KiGGS). British Journal of Clinical Pharmacology. 2009;68(4):599-608.

6. Administration USFDA. FDA considers expanding definition of nonprescription drugs [cited 2013 28th Feb 2013]. Available from:

http://www.fda.gov/Drugs/ResourcesForYo u/SpecialFeatures/ucm297128.htm.

7. Mohamed Saleem TK, Dilip CSC, Azeem AK. Self medication with over the counter drugs: A questionnaire based study. Der Pharmacia Lettre. 2011;3(1):91-8.

8. Wazaify M, Shields E, Hughes CM, McElnay JC. Societal perspectives on overthe-counter (OTC) medicines. Family Practice. 2005;22(2):170-6.

9. Bodeker G, Kronenberg F. A public health agenda for traditional, complementary, and alternative medicine. American Journal of Public Health. 2002;92(10):1582-91.

10. Tabuti JR, Kukunda CB, Kaweesi D, Kasilo OM. Herbal medicine use in the districts of Nakapiripirit, Pallisa, Kanungu, and Mukono in Uganda. Journal of Ethnobiology and Ethnomedicine. 2012;8:35.

11. Osaka R, Nanakorn S. Health care of villagers in northeast Thailand--a health 
diary study. The Kurume Medical Journal. 1996;43(1):49.

12. Shankar P, Partha P, Shenoy N. Selfmedication and non-doctor prescription practices in Pokhara valley, Western Nepal: a questionnaire-based study. BMC Family Practice. 2002;3(1):17.

13. Thomas D, Noyce PR. The interface between self medication and the NHS. British Medical Journal. 1996;312(7032):688.

14. Aoyama I, Koyama S, Hibino H. Selfmedication behaviors among Japanese consumers: sex, age, and SES differences and caregivers' attitudes toward their children's health management. Asia Pacific Family Medicine. 2012;11(1):7.

15. Stein C, Gora N, Macheka B. Self-medication in urban and rural Zimbabwean communities. British Journal of Clinical Pharmacology. 1989;27(6):7417.
16. Yousef A-MM, Al-Bakri AG, Bustanji Y, Wazaify M. Self-medication patterns in Amman, Jordan. Pharmacy World \& Science. 2008;30(1):24-30.

17. Stjernberg L, Berglund J, Halling A. Age and gender effect on the use of herbal medicine products and food supplements among the elderly. Scandinavian Journal of Primary Health Care. 2006;24(1):50-5.

18. Lam A, Bradley G. Use of selfprescribed nonprescription medications and dietary supplements among assisted living facility residents. Journal of the American Pharmacists Association: 2005;46(5):57481.

19. Glover DD, Amonkar M, Rybeck BF, Tracy TS. Prescription, over-the-counter, and herbal medicine use in a rural, obstetric population. American Journal of Obstetrics and Gynecology. 2003;188(4):1039-45 